\title{
A rare case of symptomatic os supranaviculare in a sportsman
}

\author{
Rajkumar S Yalawar ${ }^{1}$, Dipu Bhuyan ${ }^{2}$, Ramesh Desai ${ }^{1}$, Gautam Goswami ${ }^{2}$ \\ ${ }^{I}$ Department of Radiology, SSIMS \& RC, Davangere, Karnataka, India. \\ ${ }^{2}$ Department of Radiology, Gauhati Medical College and Hospital, Guwahati, Assam, India.
}

\begin{abstract}
Os supranaviculare or Pirie's bone is located on the dorsal aspect of the talonavicular joint at midpoint of foot. This rare incidental skeletal variant when symptomatic often misdiagnosed as avulsion fracture of navicular or talar head. We report a rare case of symptomatic os supranaviculare in a 27 year old football player who had fall from bike in recent past presented with dorsal foot pain and swelling since 4 months. Magnetic resonance imaging findings in right foot illustrated well corticated ossicle dorsal to talonavicular joint with surrounding soft tissue swelling. Brief discussion on differentiating it from avulsion fracture, differential diagnosis of dorsal foot pain and treatment options was made in our case report.
\end{abstract}

Key Words: Dorsal foot pain, Os supranaviculare, Pirie bone, Football player

\section{Introduction}

Accessory ossicles are supernumerary bones that commonly derive from unfused primary or secondary ossification centers ${ }^{2}$. Os supranaviculare is a rare incidental skeletal variant with low prevalence of 1 to $3.5 \%$ in the foot ${ }^{4}$. Its functional role is unknown. They are usually asymptomatic and rarely symptomatic. Symptomatic os supranaviculare is a rare cause of dorsal foot pain and often misdiagnosed as a cortical avulsion fracture of navicular or talar head in clinical scenario of trauma. Tendinitis, Neuritis, stress fracture, ankle sprain are considered for differential diagnosis in dorsal foot pain ${ }^{12}$. Management includes both conservative and surgical treatment options.

Very few radiological literature are available either due to rare entity or misdiagnosed as an avulsion fracture of navicular bone or talar head in trauma conditions. Though rare, symptomatic os supranaviculare needs to be differentiated from other conditions of dorsal foot pain by clinical and radiological investigations for better management.

We report a rare case of symptomatic os supranaviculare in a 27 year old football player who had fall from bike in recent past presented with dorsal foot pain and swelling since 4 months.

\section{Case Report}

A 27 year old male football player presented with right dorsal foot pain and mild swelling since 4 months. He had fall from bike 6 months back. Ankle pain was relieved by rest and analgesic. Pain was increased during football playing and subsequently limited his sport activity due to swelling. Initially neglected this issue and finally reported to the hospital. On inspection mild swelling was noted in dorsum of foot without any sign of skin erythema. On palpation local tenderness was demonstrated and his pain exaggerated during plantar flexion. Radiograph of right foot was advised to check for any bony injury (figure 1). No obvious bone injury was noted. Instead a well corticated small ossicle dorsal to talonavicular joint - os supranaviculare with mild soft tissue swelling was noted. Contralateral side radiograph of foot was normal. Magnetic resonance imaging (MRI) was suggested for further evaluation to know the exact cause. MRI of right foot illustrates small ossicle in the supranavicular region on T1 weighted image and Short tau inversion recovery (STIR) sequences (figure 2). Minimal soft tissue edema and inflammatory changes was noted adjacent to os supranaviculare on STIR sequence (figure 3). Ligaments and tendons were normal. No evidence of ankle joint effusion. Visualized tarsal bones shows normal signal intensity. Thus differentials like tendinitis, neuritis and stress fracture were excluded and confirmed symptomatic os supranaviculare on MRI imaging.

Conservative treatment was started initially by applying crepe bandage to ankle and proximal foot and advised to take rest from sport activities. Analgesic and anti-inflammatory medications were prescribed for a week. Still pain persisted after one week for which steroid injection was given at the maximum tenderness region.

Follow up after 6 week showed no swelling in dorsum of foot and patient was asymptomatic. After 2 month he resumed his normal sport activity. 


\section{Discussion}

Most accessory ossicles of the foot remain asymptomatic, however can cause painful syndromes, suffer or simulate fractures. Accessory ossicles can be affected by trauma, infection, degenerative disease and osteonecrosis ${ }^{11}$. The most common accessory ossicles were accessory navicular $(11.7 \%)$, os peroneum $(4.7 \%)$, os trigonum $(2.3 \%)$, os supranaviculare $(1.6 \%)$, os vesalianum $(0.4 \%)$, os supratalare $(0.2 \%)$ and os intermetatarseum $(0.2 \%)^{3}$. The supranaviculare ossicle also known as os talonavicular dorsale, talonavicular ossicle or Pirie's bone is located on the dorsal aspect of the talonavicular joint at midpoint of foot ${ }^{2,8}$. It is a rare skeletal variant and prevalence varies from 1 to $3.5 \%{ }^{4,9}$. The os supranaviculare may fuse with the navicular to form a spur of no clinical significance ${ }^{3}$. Symptomatic os supranaviculare may be misdiagnosed as the cortical avulsion fracture of the navicular bone or talar head ${ }^{1}$.

Clinical examination, pain localization, mechanism of injury or overuse along with radiological investigations were helpful for correct diagnosis. Radiographs was the initial investigation to identify the presence of an ossified accessory bone or suspicious fracture. Cartilaginous or non-ossified accessory bones may be identified on ultrasound and in addition useful in assessing adjacent soft tissues changes of inflammation or injury ${ }^{5,6}$. Sometimes scintigraphy can be used to localize the dorsal foot pain. Computed tomography plays role in demonstrating fracture, degenerative changes at a synchondrosis or sclerosis. Magnetic resonance imaging (MRI) is most useful and problem solving stool in differentiating painful syndrome from avulsion fracture of navicular or talar head ${ }^{1,7}$.

Sports activity like kicking of the football and anatomical location of ossicle was the most common cause for symptomatic os supranaviculare. As os supranaviculare is very small ossicle and sometime difficult to identify sustained injury or inflammatory changes. In our case MRI of the foot shows a well-corticated oval or triangular ossicle with smooth borders dorsal to talonavicular joint to confirm it as os supranaviculare. In literature, avulsion fracture is described as small flake of bone or bony chip with poorly corticated irregular margins and surrounding soft tissue swelling ${ }^{10}$. Occupation and mechanism of injury are important clue to consider and usually seen in snowboarding injuries or middle aged women who wear high heeled shoes ${ }^{10}$.

Management includes both conservative and surgical treatments. Conservative treatment includes immobilization of the foot with bandage or tape, anti-inflammatory medication, physical therapy. If pain persists, steroid injection on the localized area in the alterative therapy. Surgery is preferable in recurrent conditions and best outcome is seen in young patients. In our case conservative treatment gave good result. So surgery was not opted. Patient was symptom free and resumed his routine work after a short layoff. It is important to differentiate this condition with avulsion fracture, as latter requires aggressive treatment in order to prevent serious long-term sequel formation ${ }^{10}$.

\section{Conclusion}

Clinical significance of Os supranaviculare in the foot is probably minor but in symptomatic condition may lead to misdiagnosing as an avulsion fracture. This case highlights the importance of the anatomical knowledge of the os supranaviculare and differentiating it from avulsion fracture. MRI was used as a problem solving tool and should be used in concert with clinical findings to guide proper management. Symptomatic os supranaviculare case reports are rare in literature and therefore may be considered in the differential diagnosis of dorsal foot pain.

\section{Acknowledgement:}

Dr. Harsha Chadaga and Dr Shalini Govil for their guidance and support. Fund Support: Nil. Conflict of interest: None.

\section{References}

[1]. Mellado JM, Ramos A, Salvadó E, Camins A, Danús M. Accessory ossicles and sesamoid bones of the ankle and foot: imaging findings, clinical significance and differential diagnosis. European Radiology 2003 13: L164-L177.

[2]. Sarrafian SK. Osteology. In: Sarrafian SK (ed). Anatomy of the foot and ankle. $2^{\text {nd }}$ edition. Philadelphia: Lippincott; 1993: P 89112 .

[3]. Coskun N, Yuksel M, Cevener M, Arican RY, Ozdemir H, Bircan O. Incidence of accessory ossicles and sesamoid bones in the feet: a radiographic study of the Turkish subjects. Surg Radiol Anatomy 2009.31:19-24.

[4]. Cilli F, Akcaoglu M. The incidence of accessory bones of the foot and their clinical significance. Acta Orthopaedica et Traumatologica Turcica 2005. 39: 243-246.

[5]. Brigido MK, Fessell DP, Jacobson JA, Wildman DS, Craig JG, Jamadar DA. Radiography and US of os peroneum fractures and associated peroneal tendon injuries: initial experience. Radiology 2005. P.235-241.

[6]. Miller TT. Painful accessory bones of the foot. Seminar in Musculoskeletal Radiology 2002. 6:153-161.

[7]. Karasick D. Fractures and dislocations of the foot. Seminar in Roentgenology 1994. 29:152-175.

[8]. Gottlieb C, Beranbaum SL. Pirie's bone. Radiology 1950. 55: 423-424.

[9]. Keats TE. The foot. In: Keats. TE, editor. Atlas of normal roentgen variants that may simulate disease. St. Louis: Mosby-Year Book; 1992. p. 615-704. 
[10]. Bayramoglu A, Demiryürek D, Firat A, Oznur A. Differential diagnosis in a professional basketball player with foot pain: is it an avulsion fracture or an os supranaviculare? Eklem Hastalik Cerrahisi. 2009; 20(1):59-61.

[11]. O. Kenechi Nwawka, Daichi Hayashi, Luis E. Diaz, Ajay R. Sesamoids and accessory ossicles of the foot: anatomical variability and related pathology. Insights Imaging (2013) 4:581-593.

[12]. Mustafa Uslu, Mehmet Arıcan, Besir Erdogmus. A Rare Case of Os Supranaviculare or Pirie's Bone in the Pediatric Patient: A Case Report. The Foot and Ankle Online Journal 2012. 5 (10): 1.

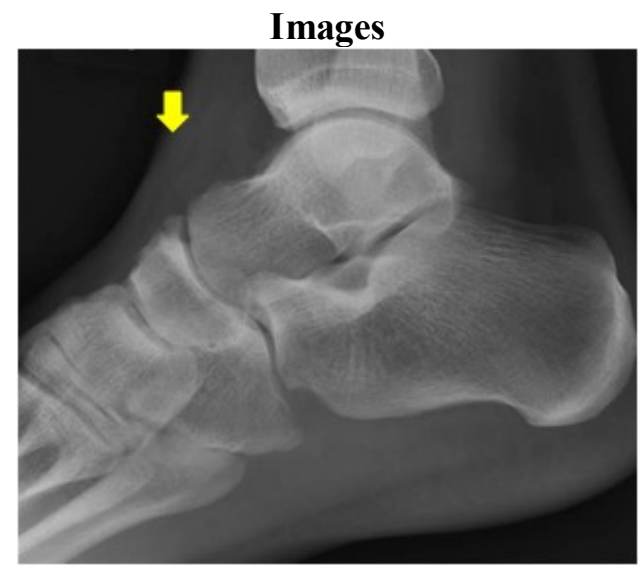

Figure 1. Radiograph of right foot shows os supranaviculare dorsal to talonavicular joint at midpoint.

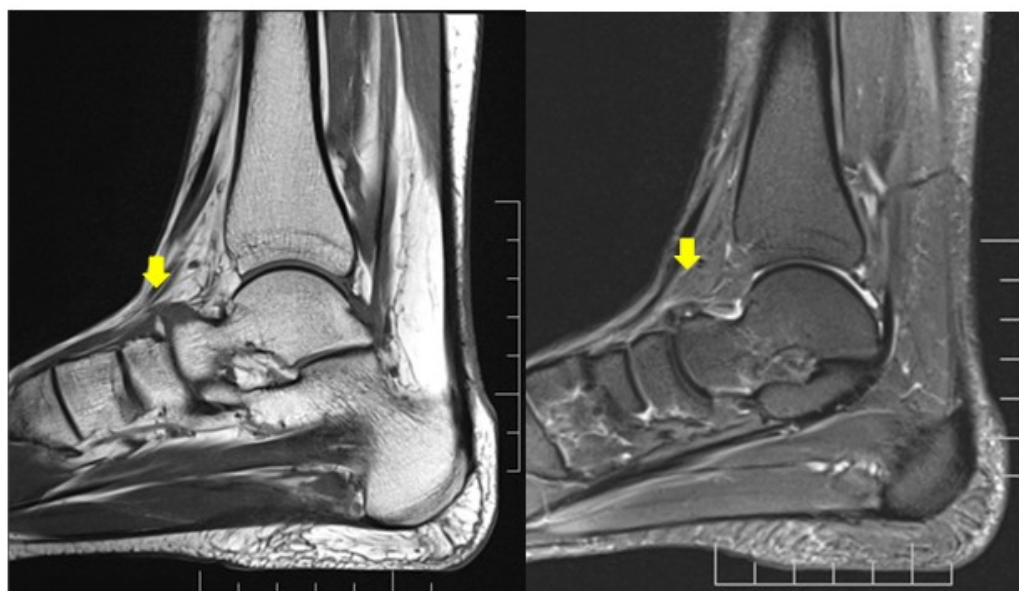

Figure 2. Magnetic resonance imaging of right foot (A) and (B). A. Sagittal T1 weighted image shows well corticated triangular ossicle with smooth borders dorsal to talonavicular joint. B. Short tau inversion recovery (STIR) image shows soft tissue swelling surrounding os supranaviculare.

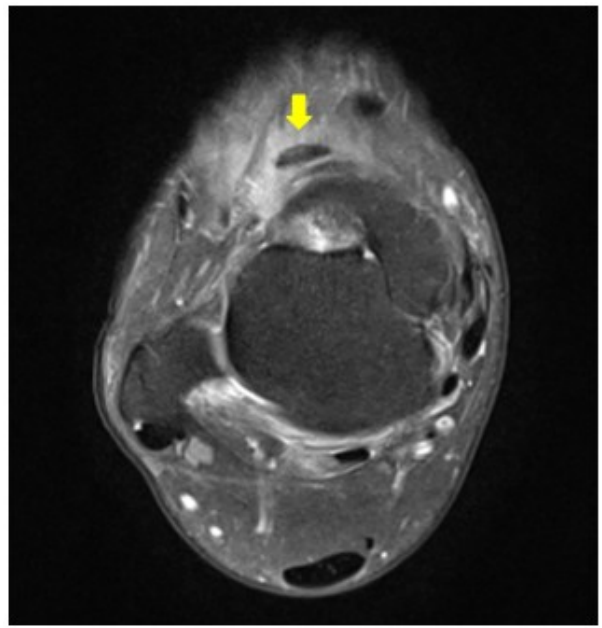

Figure 3. Short tau inversion recovery (STIR) image shows soft tissue swelling surrounding os supranaviculare. 